DOI: 10.12957/demetra.2016.22472

\title{
Gordinha da Silva: análise discursiva acerca do corpo feminino considerado gordo no universo dos blogs
}

\section{Gordinha da Silva: a discourse analysis of the female body deemed as fat in the blogging environment}

\author{
Silvana da Silveira Campos' \\ Francisco Romão Ferreira' \\ Cristiane Marques Seixas' \\ Larissa Escarce Bento Wollz ${ }^{2}$ \\ 1 Universidade do Estado do Rio de Janeiro, \\ Instituto de Nutrição, Programa de Pós- \\ Graduação em Alimentação, Nutrição e Saúde. \\ Rio de Janeiro-RJ, Brasil. \\ ${ }^{2}$ Centro Universitário Augusto Motta, Curso de \\ Psicologia. Rio de Janeiro-RJ, Brasil. \\ Correspondência / Correspondence \\ Silvana da Silveira Campos \\ E-mail: ssilcamposs@gmail.com
}

\section{Resumo}

A partir de um olhar das ciências humanas e da saúde, o artigo tem por objetivo analisar os sentidos do corpo feminino considerado gordo, utilizando como objeto de estudo blogs de pessoas que se dizem gordas. O método utilizado no estudo foi a análise do discurso. Para construir o corpus de pesquisa, recorremos a blogs públicos na plataforma Blogger. As categorias de análise foram feitas a partir de postagens e títulos com palavras relacionadas à gordura, ao peso e à imagem do corpo. Os resultados sugerem que a problemática do corpo gordo no contexto estudado vai além da necessidade de perder gordura ou diminuir o peso. Os discursos dos blogs revelam também a busca por um corpo específico, modelado e que atenda aos interesses do mercado. Um corpo estilizado e midiático que recorre aos variados artifícios que o mercado da saúde, da estética e da tecnologia disponibilizam, tais como aplicativos móveis (app) para dieta e exercício; cirurgias de redução de estômago (gastroplicatura, gastroplastia); silicones para hipertrofia dos músculos. Os discursos também expressam urgência na busca pela transformação dos corpos gordos. O corpo gordo que não se transforma é significado nos blogs como algo estagnado e obsoleto.

Palavras-chave: Corpo. Obesidade. Estigma Social. Blogs. Saúde.

\section{Abstract}

The purpose of this article, from the perspective of Human Sciences and Health Sciences, is to analyze the meaning of the female body deemed as fat, using blogs of people who self-report 
as fat as the object of study. The method used in the study was discourse analysis. The research corpus was designed with texts from public blogs published on the platform Blogger. The categories of analysis were based on posts and titles with words related to fat, weight and body image. The results suggest that the issue of a fat body in the context of the present study goes beyond the need to lose fat and weight. The discourses on the blogs show a quest for a particular, shaped body image, in order to meet the interests of the market. It is a media's perfect, stylized body which makes use of the several resources made available by the health, esthetics and technology markets, such as mobile applications for dieting and exercising purposes; stomach reduction surgery (e.g. gastroplication, gastroplasty); silicone implants for muscle hypertrophy. The discourses also express immediacy in the quest for transformation of fat bodies. A fat body that does not undergo transformation is signified in blogs as something stagnant and obsolete.

Key words: Body. Obesity. Social Stigma. Blogs. Health.

\section{Introdução}

Numa sociedade de mercado, onde a indústria do consumo reina soberana e divulga imagens de sucesso e saúde associadas a corpos belos, magros, padronizados, manipulados e transformados, o corpo gordo, principalmente do sexo feminino, parece ser o alvo fácil de uma vigília constante.

O senso comum, informado por um discurso biomédico que valoriza a estetização da saúde, processo no qual são utilizados critérios da medicina estética, da moda e da beleza construída nas academias como parâmetros para avaliar saúde, ${ }^{1}$ identifica aleatoriamente o corpo gordo como obeso, um corpo doente que precisa ser emagrecido. Muitas vezes, é uma imposição que reforça estigmas que pesam e prejudicam mais que a própria gordura.

Segundo Poulain, ${ }^{2}$ o corpo gordo é estigmatizado por ser diferente, e é considerado um desviante por não estar de acordo com a ordem médica. Por conta disso, é naturalizado no cotidiano como um corpo "errado", fora do padrão "normal". A sociedade, porém, desconsidera que o que é considerado normal é também um valor mutável, e o que hoje é considerado gordo e feio já foi considerado "cheinho", volumoso e sexy num passado recente. ${ }^{3}$

A mulher gorda sofre de distúrbios com a própria imagem, influenciadas por uma ditadura da beleza que, amparada pela mídia, celebra as práticas restritivas e reformatórias do corpo feminino 
como cuidados saudáveis e invejáveis, culpando e ridicularizando aquelas que não seguem. Além disso, mesmo sem necessidade, a ideia de "quanto mais magra, melhor" é sempre reforçada. ${ }^{4}$ Obesidade e excesso de peso assumem sentidos que se misturam e se confundem nos vocabulários da saúde e da estética.

O ambiente sociocultural e a mídia têm forte influência sobre a imagem que o sujeito constrói sobre o próprio corpo e o ideal de corpo que ele gostaria de ter. Se a imagem valorizada socialmente é de magreza, emagrecer será o ideal de todos, e aqueles que não conseguem geralmente têm maior insatisfação e sofrimento. Nesse sentido, a imagem corporal vai sendo construída a partir do contato que o corpo tem com experiências externa. O corpo registra e assimila vivências e também sofre as marcas do tempo. Essa construção de imagem é uma experiência ativa, que se modifica ao longo do tempo, a partir das mudanças de olhar para o mundo, para os outros e para si mesmo. ${ }^{5}$

Explorar os discursos de blogs é falar do universo subjetivo da gordura e desvelar sentidos naturalizados nas ditaduras, estigmas e imposições desmedidas sobre o corpo. Ao escolhermos o espaço da internet, buscamos na cultura o que está sendo dito hoje sobre o gordo, discursos que extrapolam e reverberam do perímetro da linguagem da doença/saúde (consultórios e clínicas).

O espaço cibernético funciona na contemporaneidade como um modo de existência completo. Um lugar com uma linguagem própria, dotado de culturas e utopias, e que permite o desenvolvimento de um mundo imaginário de sentidos. Um mundo em que as fronteiras são misturadas e o corpo é invisível. Seria como um reino de libertação das limitações do corpo, onde o corpo se encontra entre parênteses. O peso dos corpos torna-se leve como nuvem. Como expõe Le Breton, o espaço cibernético liberta o indivíduo das coerções da identidade, metamorfoseia-o provisoriamente no que ele quer ser, sem temer o desmedido do real. Sem rosto, não há mais que ter medo de não conseguir olhar para si mesmo; ele está livre de qualquer responsabilidade, já que sua identidade é volátil. ${ }^{6}$

Blog, seguindo o original termo inglês "web + log", seria o resultado de uma contração do termo "web" (do original "World Wide Web", sinônimo de internet) com "log" ("endereço" ou "registro"). Ou seja, um log na web, ou um pequeno espaço dentro do gigante universo da comunidade virtual. Espaço onde seria possível expressar ("postar") experiências pessoais, opiniões, sentimentos e pensamentos sobre variados temas. Espaço de possibilidades para expor segredos..$^{7-9}$

O objetivo deste artigo foi analisar, a partir de um olhar das ciências humanas e da saúde, os sentidos do corpo feminino gordo na sociedade contemporânea, utilizando como objeto de pesquisa o discurso dos blogs de pessoas que se identificam como gordas. 


\section{Metodologia}

O método utilizado no estudo foi análise do discurso. Pela análise do discurso, segundo Eni Orlandi, ${ }^{10}$ é possível compreender como um objeto simbólico produz sentidos. Nesse entendimento, discurso é o ritual das palavras em movimento e prática de linguagem. Além disso, o discurso está investido de significâncias pelos e para os sujeitos do discurso.

Discurso aqui não trata apenas de transmissão de informação, mas de um processo de identificação do sujeito e de construção de realidade. Discurso não é somente fala; é um sistema que só existe dentro de um contexto social e histórico, subjetivo e objetivo.

Para construir o corpus desta pesquisa, recorremos a recortes de postagens de blogs públicos da plataforma Blogger. As categorias de análise foram feitas a partir de postagens e títulos com palavras relacionadas à gordura, ao peso e à imagem do corpo.

A seguir, descrevemos o repertório de perguntas que foram úteis para identificarmos elementos no discurso dos blogs que servissem como um caminho para construirmos nossas categorias de análise e, a partir delas desenvolvermos, a discussão teórica ancorados na literatura das ciências humanas e biomédicas: a) Quais as falas depreciativas? b) Quais as metáforas utilizadas para representar o corpo? c) Que palavras relacionadas à autoimagem/aparência do corpo apareciam? d) Qual o padrão que aparece como modelo de corpo? e) Quais os termos recorrentes do universo da gordura/obesidade no período do estudo? f) Quais as palavras e frases relacionadas à condição de ser gordo (estigma)?

\section{Resultados e discussão}

Através da análise dos discursos, é possível compreender que cada categoria pode representar um elo na rede de sentidos e significados do universo da gordura contemporânea; elos que são constantemente produzidos e reproduzidos. Em seguida, descrevemos algumas categorias que foram escolhidas para desenvolvermos a discussão deste trabalho:

\section{A fala depreciativa}

"Me odeio, sou obesa!"11

"Ninguém quer ser gordo. Assim como ninguém quer ser feio, ou pobre. Todo mundo quer ser vencedor, e só há um tipo de vencedor, certo?"I2

"Lixo humano"ll 
As palavras utilizadas para falar do próprio corpo nos blogs podem ter diferentes interpretações. Um dos aspectos que chama atenção nos blogs é a fala de um corpo desvalorizado, que é associado a um produto sem utilidade no mercado, objeto descartável, tal qual o lixo. Há de se entender que, numa sociedade de mercado, onde tudo pode ser consumido e vendido, o corpo também é um produto. Conforme colocam Vieira \& Bosi, ${ }^{13}$ o corpo desejado de hoje é o corpo sintético, milimetricamente calculado, tecnológico e projetado para eficiência, numa eterna confecção. É isso que garantirá a ele a possibilidade de permanecer sendo desejado.

Na descoberta de que o desejo não pode ser saciado, outros produtos são lançados, no eterno modismo que autentica dialeticamente o obsoleto de ontem. Cabe acrescentar também que nesse sistema, baseado em constantes processos de construção e reconstrução de produtos, o insucesso, após tentativas de transformá-lo num produto vendável, é tido como fracasso pessoal.

Para Le Breton, ${ }^{14}$ o corpo tornou-se um objeto imperfeito, um rascunho a ser corrigido. $\mathrm{O}$ corpo a que ele se refere é um corpo que cada vez mais vem sendo transformado em máquina, sem sujeitos nem afetos. Neste sentido, o corpo não é mais apenas a encarnação irredutível do sujeito, o ser-no-mundo, mas uma construção, um objeto transitório e manipulável. Deixou de ser identidade de si para se tornar um kit, uma soma de partes. A exterioridade do sujeito reduziu-se a sua superfície e qualquer tentativa de mudar o corpo seria também uma tentativa de mudar de vida.

\section{Metáforas}

"biquini de lacinho"15

Como reporta Vigarello ${ }^{16}$ "no século XVII, a "dama do palácio” recorria às roupas para contrabalancear os excessos, usava espartilhos, faixas ou camisolas para tornar a cintura fina, espetada e mais esbelta”. Ou seja, naquele contexto, a gordura tinha os recursos de modelagem a seu favor.

O século XX encurtou e remodelou os vestidos, desvelando um corpo que estava escondido. O mercado atual, porém, não sugere, dita. Se antes os acessórios e a moda estavam à disposição do corpo, hoje o corpo precisa se amoldar à modelagem. Nesse processo não há muitas opções; é ele que deve ser reparado, costurado e reconstruído aos moldes que o mercado impõe.

Por exemplo, biquíni de lacinho dá nome a um blog de uma pessoa que se identifica como gorda. A peça de vestuário feminino escolhida como nome não é qualquer peça, é um biquíni pequeno, ou melhor, bem pequeno. Um produto do universo da moda fabricado para um corpo padrão e que remete a um tipo de corpo ideal. Um biquíni de lacinho pode ser também significado como ícone de magreza. O objeto de desejo anuncia que tudo deve valer para que o corpo caiba nesse produto. Estar gordo neste contexto é estar fora das medidas, é não caber naquilo que o mercado atual oferece. 
Outra forma de analisar esta situação é a partir da visão de Bauman, ${ }^{17}$ que define a sociedade de consumidores. Segundo ele, representa um tipo de sociedade que promove, encoraja e reforça a escolha de um estilo de vida e uma estratégia existencial consumista, rejeitando todas as opções culturais alternativas. Nessa sociedade, adaptar-se aos preceitos da cultura de consumo e segui-lo direitinho é o propósito vital e a única escolha aprovada de maneira incondicional. Além disso, a vocação consumista se basearia nos esforços individuais. Seria o consumidor quem deveria se adequar à oferta restrita do mercado e assim sentir-se adequado, eficiente e dentro dos padrões. Importante também entender que há um pronunciamento de oferta pra "todos os gostos", mas o espaço no social será de livre acesso somente àqueles que consomem determinados produtos (modelos).

"poderosa nos provadores de roupa ou na lingerie do dia dos namorados"18

Ser "poderosa nos provadores de roupa ou na (sic) lingerie do dia dos namorados" parece ser uma tentativa de fazer parte de um espaço restrito aos corpos magros. Num estudo sobre a história do corpo, Mary Del Priore destaca a influência do mundo da moda no corpo feminino. O início do século XX trouxe junto o apogeu da moda da mulher magra. O famoso costureiro francês Paul Poiret rompeu com o modelo de ancas majestosas. O tamanho das roupas passou então a determinar a largura e a conformação do corpo em relação às roupas, tornando-se uma espécie de forma anatômica. Não caber numa determinada roupa traduzia um constrangimento moral e não apenas corporal. O tamanho traduzia, num martírio mental, a linha de demarcação que passara a reprovar e estigmatizar toda mulher que a extrapolasse. ${ }^{19}$

Lipovetsky, ${ }^{20}$ porém, coloca que a sociedade contemporânea estaria vivenciando um período do capitalismo transestético; seria um momento de hiperconsumo, quando o estilo, o design de produtos e a beleza se impõem como imperativos estratégicos de grandes marcas que apelam para emoções e para o senso estético dos seus clientes e consumidores. Tudo teria que ser embelezado, desde escova de dente, papel higiênico, utensílios domésticos até os corpos. Há uma cobrança geral para o embelezamento do mundo, um hiperdesign de produtos; o apelo às emoções numa tentativa de seduzir pelo prazer visual. Além disso, uma forte imposição de rapidez para que as transformações aconteçam.

Nesse movimento veloz, parece que o corpo gordo não seria um manequim ideal, tal como uma boa arara de roupas, tampouco boa vitrine para expor roupas e acessórios. Indo mais adiante, o corpo gordo, seguindo a lógica de Lipovestsky, poderia não "combinar" com a lógica da hiperestilização, já que não seria massa fácil para ser transformada, moldada, estilizada. Neste contexto, este formato de corpo tornar-se-ia então objeto obsoleto. 


\section{Modelos de corpo}

"Porque todas nós somos panicats em potencial"18

Os discursos dos blogs revelam que os modelos de corpo a serem seguidos são os formatos dos corpos da mídia. Modelos, apresentadoras de programas de televisão, atrizes de novela, pessoas que circulam pelos meios de comunicação, celebridades.

Um dos modelos escolhidos para essa discussão foi panicat. O termo panicat faz referência a uma mulher jovem, seminua, que é assistente de palco de um programa exibido num canal de televisão brasileiro. É uma espécie de chacrete moderna. Chacretes eram antigas dançarinas, ajudante de palco, que dançavam seminuas, em um programa de auditório da TV brasileira, o Cassino do Chacrinha. ${ }^{a}$ Segundo a postagem, potencialmente, todas (as mulheres) poderiam ficar com o corpo de uma panicat, ou uma chacrete. Todo corpo poderia chegar a este padrão e assim fazer parte de um estilo de vida, da mídia, do popular, do visualizado. Mudar para ocupar o palco, ou a cena. Teoricamente, todas as mulheres consideradas gordas poderiam ser transformadas e visualizadas no tal mundo "normal" - afinal, como diz o ditado popular, "só é gorda quem quer".

Os meios de comunicação de massa teriam participação ativa no cotidiano das pessoas, ${ }^{21,22} \mathrm{com}$ ampla capacidade de inserir e divulgar bens simbólicos no imaginário coletivo. Essa participação "ativa" no cotidiano acontece diariamente, de forma intermitente e exaustiva através de imagens e representações de ideais de corpos e hábitos, instigando um consumo destes modelos pela sociedade. $^{13}$

Bourdieu ${ }^{21}$ ajuda a perceber este fenômeno quando fala de um poder símbólico que é capaz de difundir um consenso sobre os sentidos da sociedade. De forma sutil, esse poder simbólico contribuiria aos poucos para a reprodução de uma ordem social. Seria um poder imperceptível e silencioso. Dessa forma hiperdiscreta, ele iria se difundindo e promovendo o consumo de atitudes e imagens, além de induzir formas de pensar, modos de ser e de se comportar.

Se para participar deste jogo o corpo real, classificado como gordo, não é adequado, então o sentido da vida se direciona para a transformação do corpo gordo ou "fora das medidas" num modelo da mídia, uma busca por um corpo que possa jogar socialmente. No entanto, nem sempre há a real percepção de como atingir a imagem ideal. Assim, a mágica dos recursos estéticos se apresenta como uma solução bem próxima, prática e ideal. Lopes e Bosi ${ }^{13}$ acrescentam, porém, que esses ideais de corpos serão sempre aqueles impossíveis de serem atingidos e que exigirão também altas quantias de dinheiros.

a Programa de auditório da Rede de televisão brasileira: TV Globo, apresentado por Aberlado "Chacrinha" Barbosa entre 1982 e 1988. 
Os modelos transmitidos pelo bombardeio de imagens da mídia são diariamente comparados aos autorretratos contemporâneos, os selfies. Os selfies aparecem como o registro de um desejo para que o corpo desconhecido seja visualizado e reconhecido. Seria também o registro dessa busca viciante pela imagem ideal do que está na superfície. Se a subjetividade não é reconhecida como possibilidade de estar no mundo, e o corpo real passa despercebido em vários espaços, a imagem do selfie parece ser um caminho para sair da invisibilidade. Mesmo que o resultado desta batalha, muitas vezes, possa ser uma percepção de fracasso, uma insatisfação, um cansaço, uma sensação de desvio, um distúrbio de imagem crônico. Distúrbios de imagem entendendo-os, ${ }^{23}$ como uma alteração grave e persistente na forma como o indivíduo percebe seu próprio corpo.

Retomando a questão sobre o corpo panicat, transformar-se numa panicat não é tornar-se apenas magra, é tornar-se construída. Uma panicat é expressão de todos os artifícios disponíveis para venda ou consumo no mercado da estética (prótese de seios, glúteos, panturrilhas, mega hair, cílios postíços, bronzeamento artificial, unhas de acrigel etc...) e dos medicamentos (esteroides e anabolizantes). É um corpo de mulher com forte apelo erótico, mas que remete ao masculino. Músculos em excesso, voz grossa, estereótipo de homem forte, macho, um gladiador. Um corpo grande e também pesado; no entanto, o peso aí não vem da gordura, mas dos músculos e das próteses.

Dizer que "Todas nós somos panicats em potencial", tal como num dos blogs visitados, é também dizer que todas são clientes em potencial da indústria da metamorfose. É uma transformação que ultrapassa o simples desejo de emagrecer. É “engostosar”, tornar-se comestível sem ser comida. É ir além, metamorfosear-se e virar outra coisa.

Para Ferreira, ${ }^{1}$ a metamorfose do corpo seria como uma nova face da transformação da vida cotidiana em algo individualizado, onde os corpos seriam metamorfoseados em objetos descartáveis no universo do consumo. O vazio da existência seria substituído pelo desejo da transformação. Essa transformação englobaria, antes de tudo, uma velocidade. O tempo, curto e veloz, teria papel fundamental nesse processo. Não haveria mais tempo para gordura. Gordura tem um sentido de tempo parado; gordura denota o estático, o que requer mais tempo, o que perdura. Estar gordo é estar estacionado, é estar dormindo; quem é gordo, nessa concepção, deve ser acordado!

\section{A condição de ser gordo hoje}

"o gorda ridícula, vê se acorda, seu tempo está se acabando!"11

"magra pra sempre"24 
Analisar um discurso, segundo Orlandi, ${ }^{10}$ é também partir do pressuposto de que os sinônimos, as metáforas e as paráfrases são reflexos da historicidade da língua. $\mathrm{O}$ analista deve encontrar, então, no texto sinais de interpretação que formam sua historicidade.

Questões relacionadas ao tempo e à velocidade cotidiana, típicas da vida contemporânea, estão expressas nos discursos. Uma vivência baseada num ritmo veloz, sem espaço para a reflexão, para o cansaço, para a pausa, para outros ritmos. A batida parece que precisa ser a mesma pra todos, numa busca progressiva pelo maior desempenho, maior velocidade, sobretudo controlada. Uma intensa frequência, sem parar, tal como uma máquina moderna ou um aplicativo eletrônico, hipermoderno.

\section{[...] numa tradução minha, Myfitnesspal será um companheiro... também um controlador de peso... ${ }^{13}$ \\ [...] usando o Wii fit, pois atualmente é a minha balança mais precisa... ${ }^{13}$}

Não há como separar a Internet e as tecnologias digitais do cotidiano das pessoas na contemporaneidade. Como sustenta Le Breton:14 "o vocabulário informático penetra as maneiras de explicar o homem e seu corpo. Apagam-se as fronteiras entre a carne do homem e o poder da máquina, entre os processos mentais e técnicos".

O uso da tecnologia digital na forma de aplicativos vem sendo descrito como mais um recurso para facilitar e transformar de maneira muito veloz o modo como as pessoas vivem o dia a dia. A cada dia, novos aplicativos surgem, com diferentes finalidades. Contadores de calorias; calculadoras para avaliação de índice de massa corporal; calculadoras para elaboração de dieta; planos de exercício e conselhos gerais de saúde são alguns desses exemplos descritos como os facilitadores do mundo digital para a luta contra a gordura. ${ }^{25}$

Os recursos tecnológicos que apareceram nas postagens dos blogs foram os aplicativos Wii fit ${ }^{\mathrm{b}}$ e Myfitnesspal ${ }^{c}$, que contam calorias ingeridas, controlam o peso e as medidas de circunferências do corpo, avaliam diariamente quantidade de nutriente ingerida.

Estes recursos da tecnologia parecem expressar mais uma necessidade de controle externo sobre si, quando a autogestão também parece impossível. Esta dinâmica parece exemplificar o que Le Breton $^{6}$ vai chamar de Farmacologização de si que é percebida nas sociedades contemporâneas como

b É um aplicativo da plataforma Nintendo voltado para exercícios físicos e emagrecimento.

c Um aplicativo desenvolvido pela App Store que funciona como uma calculadora de calorias rápida e fácil de usar. Tem um banco de dados de alimentos com mais de cinco milhões de alimentos e com registros rapidíssimos de alimentos e exercícios. Indicado para emagrecimento, boa forma e saúde. 
técnicas de gestão de humor e de vigilância, utilizadas no cotidiano visando uma transformação do foro íntimo, com o objetivo de melhorar o poderio sobre o mundo, aguçar a capacidade de percepção, superar o cansaço, prolongar o sono ou escapar dele.

Esse processo favoreceria o desenvolvimento de um imaginário de onipotência sobre si, amplamente empregado pelos indivíduos, já que ao abandonar-se ao humor "natural", o indivíduo também se priva de uma lista de recursos, ou se torna menos competitivo no plano do trabalho ou da vida cotidiana. $\mathrm{O}$ autor coloca que o mais interessante nesse processo é que ele revela uma vontade de produzir estados afetivos sem que se coloque nem por um instante a questão da dificuldade de viver, e sim uma preocupação de decidir por conta própria.

\section{Vocabulário do universo da gordura}

“...um companheiro de RA"12

"Alguém conhece ou já fez gastroplicatura?...tem blog pra indicar?"26

"ba-ri-á-tri-ca!!!"”6

Não só as tecnologias de mídia ou o uso de psicofármacos são utilizados nesse modo techne de tentar gerir a si, mas as cirurgias de estômago (gastroplicatura, gastroplastia), RA (reeducação alimentar) e AF (atividade física) fazem parte também do que poderíamos chamar de "uma falsa gestão cotidiana de si”. Além de expressar essa necessidade, essas práticas falam também de modos voluntários de produção de si e de uma identidade pessoal. A modificação do corpo e a gestão das medidas e formas corporais criam um sentido de existência e uma falsa percepção de que o controle sobre o mundo é possível, é também uma impressão ilusória de que se pode gerir a "máquina".

Os comentários e as postagens com referências a intervenções cirúrgicas são exemplos do quanto alguns termos do universo da estética e da medicina estão naturalizados nos discursos coletivos. Seriam elementos da cultura do embelezamento. As falas revelam possibilidades rápidas de mudanças no corpo a partir desses elementos, de forma muito fácil, como se fossem mecanismos mágicos de alterações corporais.

Ferreira ${ }^{27}$ chama isso de parte do processo de estetização da saúde, em que os padrões estéticos estariam cada vez mais presentes em processos que confundem medicina estética, publicidade, desinformação, espetáculo e informação científica para o senso comum, dando uma falsa ideia de eficácia que nem sempre seria real. Ou seja, Ética, Estética e Saúde Pública estariam se confundindo e interferindo nos cuidados com o corpo, e preocupação com a beleza e com a saúde. 
Ainda segundo o autor, o crescimento de cirurgias plásticas no Brasil e a expansão da indústria de beleza, da indústria de metamorfose corporal fariam parte de um processo mais amplo de medicalização, no qual a tecno-racionalidade médica seria levada a novas esferas da vida cotidiana. Além disso, a popularização e a banalização desses procedimentos cirúrgicos levariam a novas construções de sentido sobre o corpo, colocando-o como um artefato a ser modelado, de acordo com os interesses do momento. Cabe acrescentar que o corpo colocado pelo autor não é denominado gordo ou magro; é todo corpo que estaria inserido neste contexto social, onde a estética é hegemônica.

\section{Considerações finais}

A busca pela perfeição do corpo parece não ter fim. A proposta de perceber nuance na trama de sentidos e significados que permeiam o universo da gordura no contexto da sociedade atual foi desvelando detalhes escondidos, possibilitando também variados percursos de interpretação. Considerando a complexidade que permeia a teia de sentidos e significados do universo da gordura, cabe destacar aqui alguns elementos que consideramos relevantes para a finalização do presente trabalho.

Com o desenvolvimento deste estudo foi possível perceber, nos discursos dos blogs, um conflito de imagem corporal dissimulado numa busca frenética por uma mudança corporal. Um desejo de emagrecer sinalizado como única opção de vida, urgentemente, tornar-se futura ex-gordinha (título de um dos blogs), metamorfosear-se e engostosar (título de um dos blogs) e virar magra para sempre. Quando o corpo é um instrumento de prestígio numa sociedade, a busca pela beleza se torna um imperativo absoluto. Aqueles com uma imagem de si mais vulnerável respondem a esses estímulos, julgando-se inadequados e superestimam as dimensões de seu corpo e a necessidade de transformá-los.

Apesar da tentativa para construir outro discurso, satisfazendo-se então com o corpo do tamanho GG ou querendo sentir-se "poderosa nos provadores de roupa ou no lingerie do dia dos namorados", ainda assim prevalece o discurso que diz que para estar bem consigo é preciso transformar esse corpo atual, e real, num corpo veiculado na mídia. Mesmo que a intenção em valorizar o corpo atual exista, a insatisfação por não ter um corpo das modelos, atrizes e personagens femininos de programas de TV aparece com grande frequência nos discursos.

É importante acrescentar que a problemática do corpo gordo atual, visualizada no contexto dos blogs, não está reduzida à perda de gordura ou diminuição do peso. O discurso dos blogs expressa uma busca por um tipo específico de corpo, uma imagem do corpo ideal. Imagem baseada num modelo, que caiba num biquíni de lacinho, por exemplo. Um corpo que atenda aos interesses de ofertas do mercado. Um corpo que seja hiperestilizado e midiático. Um corpo que tenha como 
principal orientação e projeto de vida a certeza de ser uma panicat em potencial. Um corpo que sabe que, além de não poder ser gordo e feio, não cabe ser pobre, pois tudo isso requer também investimentos financeiros.

Para atingir esse corpo específico, o projeto maior ultrapassa o período do verão, quando a exposição do corpo nas roupas de banho é necessária. A busca por esse corpo específico, agora, assume sentido de um projeto para toda vida. Para isso, deve fazer uso dos variados artifícios que o mercado da saúde, da estética e da tecnologia disponibiliza: os aplicativos para dieta e exercício; as cirurgias de redução de estômago (gastroplicatura, gastroplastia); silicones para hipertrofia dos músculos, além da RA (reeducação alimentar) e da AF (atividade física), agora reformuladas.

Os discursos também remetem a certa imposição e imediatismo desse movimento de transformar corpos gordos. O que poderia ser uma sugestão ou prescrição, agora é da ordem do imperativo: O dever de casa está dado! A hipertrofia é pra já! Além disso, ter um corpo considerado obeso ou gordo é, conforme postado nos blogs, estar estacionado, é ser odiado, é ser um cão esganado, é ter a urgência para mudar esse corpo "humano" e não deixar escapar o corpo "artificial” do momento.

\section{Referências}

1. Ferreira FR. Algumas considerações acerca da medicina estética. Cienc. Saúde Coletiva 2010;15(1):67-76.

2. Poulain JP. Sociologia da obesidade. São Paulo: Senac; 2013.

3. Campos SS, Ferreira FR, Seixas CM, Prado SD, Carvalho MCVS, Kraemer FB. Num relance de olhar... a estigmatização das pessoas gordas: do passado aos dias de hoje. Revista Hospital Universitário Pedro Ernesto 2015; 14(3):90-96

4. Scagliusi FB. A ditadura da beleza e suas consequencias no discurso nutricional. In: Alvarenga M, Scagliusi FB, Philippi ST. Nutrição e transtornos alimentares. Barueri: Manole; 2011. p. 59-83.

5. Schomer EZ, Kachani AT. Imagem corporal. In: Córdas TA, Kachani AT. Nutrição em psquiatria. Porto Alegre: Artmed; 2010.

6. Breton DL. O corpo supranumerário no espaço cibernético. In: Breton DL. Adeus ao corpo: antropologia e sociedade. Sao Paulo: Papirus; 2003. p. 141-161.

7. Lemos A. Cibercultura: tecnologia e vida social contemporânea. Porto Alegre: Sulina; 2004.

8. Levy P. A inteligencia coletiva. São Paulo: Loyola; 2007.

9. Monabosco GG, Romualdo EC. O blog: revisão da literatura e proposta de conceituação. In: Navarro P, Possenti S. Estudos do texto e do discurso: praticas discursivas na contemporaneidade. Sao Carlos: Pedro 7 Joao Editores; 2012.

10. Orlandi E. Analise de discurso: princípios e procedimentos. Campinas: Pontes; 2013.

11. Me Odeio, Sou Obesa! [Internet] 6 nov. 2012. [acesso em: 26 maio 2014]. Disponível em: http:// www.meodeiosouobesa.blogspot.com.br 
12. Gordinha da Silva [Internet]. 10 mar. 2014. [acesso em: 23 mar. 2015. Disponível em: http://www. gordinhadasilva.blogspot.com.br/

13. Vieira CAL, Bosi MLM. Impressões sobre o corpo feminino na interface mídia, consumo e ciência medico-estética: das imagens de papel à imaterialidade do corpo simbólico. In: Freitas RF, Ferreira FR, Carvalho MC, Prado SD. Corpo e consumo nas cidades. Curitiba: CRV; 2014. p. 65-79.

14. Breton DL. A antropologia do corpo e modernidade. Petropolis: Vozes; 2011.

15. Biquini de Lacinho [Internet]. 6 maio 2014. [acesso em: 29 set. 2014]. Disponível em: http://www. biquinidelacinho.blogspot.com.br

16. Vigarello G. As metamorfoses do gordo: historia da obesidade: da Idade Média ao século XX. Petropolis: Vozes; 2012.

17. Bauman Z. Vida para consumo: a transformação das pessoas em mercadorias. Rio de janeiro: Jorge Zahar; 2008.

18. Engostosando [Internet]. 27 dez. 2011. [acesso em: 19 set. 2014]. Disponível em: http://www. engostosando.blogspot.com.br

19. Priore MD. Corpo a corpo com a mulher: pequena historia da transformação do corpo feminino no Brasil. São Paulo: Senac; 2009.

20. Lipovetsky G, Serroy J. A estetização do mundo: viver na era do capitalismo artista. São Paulo: Companhia das Letras; 2015.

21. Boudieu, P. A produção da crença: contribuição para uma economia dos bens simbólicos. Porto Alegre: Zouk; 2006.

22. Mendonça MLM, Borges CN. O corpo como mercadoria na sociedade de consumo: saúde ou estética? In: Freitas RF, Ferreira FR, Carvalho MCVS, Prado SD. Corpo e consumo nas cidades. Curitiba: CRV; 2014. p. 47-63.

23. Sato PM, Timerman F, Fabbri AD, Scagliusi FB, Kotait MS. A imagem corporal nos transtornos alimentares: como o terapeuta nutricional pode contribuir para o tratamento. In: Alvarenga M, Scagliusi FB, Philippi ST. Nutrição e transtornos alimentares. Barueri: Manole; 2011. p. 475-495.

24. Magra pra sempre [Internet]. Disponível em: http://magraprasempre-paty.blogspot.com.br

25. Hwang KO, Ottenbacher AJ, Green AP, Cannon-Diehl MR, Richardson O, Bernstam EV, et al. Social support in an Internet weight loss community. Int. J. Med. Inform. 2010; 79(1):5-13.

26. Minha vida roliça [Internet]. 10 jan. 2012. [acesso em: 12 fev. 2015]. Disponível em: http://www. minhavidaroliça.blogspot.com.br

27. Ferreira FR. Ciência, arte e cultura no corpo. Curitiba: CRV; 2011.

Recebido: $16 / 4 / 2016$

Revisado: $12 / 7 / 2016$

Aceito: 10/8/2016 
Blogs Consultados

\begin{tabular}{|l|}
\hline http://ex-gordinha.blogspot.com.br/ \\
\hline http://eucanseidesergorda.blogspot.com.br \\
\hline http://memoriasdagordinha.blogspot.com.br \\
\hline http://gordinhadasilva.blogspot.com.br/ \\
\hline http://meodeiosouobesa.blogspot.com.br/ \\
\hline http://diariodeumagordinha.blogspot.com.br/ \\
\hline http://debemcomnossoespelho.blogspot.com.br \\
\hline http://biquinidelacinho.blogspot.com.br/ \\
\hline http://minhavidarolica.blogspot.com.br/ \\
\hline http://osdesabafosdepathy.blogspot.com.br/ \\
\hline http://seeuqueroeuvouconseguir.blogspot.com.br/ \\
\hline http://nossasgordurinhas.blogspot.com.br/ \\
\hline http://gordinhateimosa.blogspot.com.br/ \\
\hline http://engostosando.blogspot.com.br/ \\
\hline http://renata-futuraex-gordinha.blogspot.com.br/ \\
\hline http://magraprasempre-paty.blogspot.com.br/ \\
\hline
\end{tabular}

